\title{
EXPERIMENTAL STUDY OF HEAT TRANSFER AND PRESSURE DROP OF TWO-PASS TUBE BANKS
}

\author{
F. Sh. Abou-Taleb \\ Department of Mechanical Power Engineering, Faculty of Engineering, \\ Kaferelshiekh University, Egypt \\ e-mail :fauzy1957@yahoo.com
}

\begin{abstract}
Tube bandles are widely used in heat exchangers for energy carriers and cooling product process, as a cooler for compressor in gas turbine unit and refrigeration plants. Heat transfer and pressure drop of isolated two-pass tube banks bandles with baffles at different locations are experimentally studied. In the present study, five heated test tubes are located at inlet of the first pass. The test tubes are heated at different rates $(\mathrm{Q})$. The measurements are taken for the five test tubes. The length of the baffles and its location are taken into account. Also the effect of the tube banks aspect ratio is studied. From the measurements the local heat transfer coefficient and pressure drop are calculated. All the measurements are conducted at low Reynolds numbers range, $(\mathrm{Re}=1000$ to 3500$)$.

يقدم البحث در اسة معملية لانتقال الحرارة وفقد الضغط خلال مبادل حر اري ثنائي المسار مكون من مجمو عة انابيب

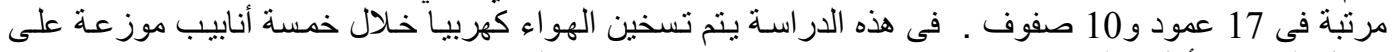

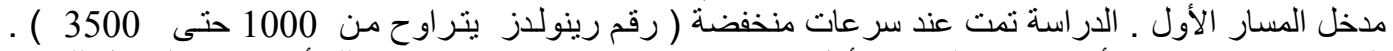

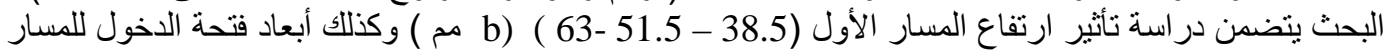

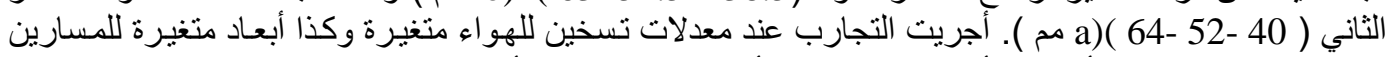

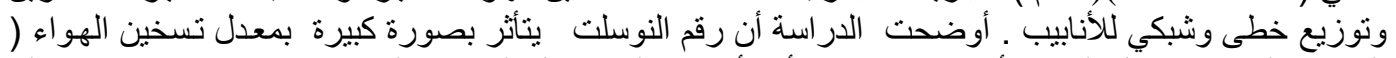

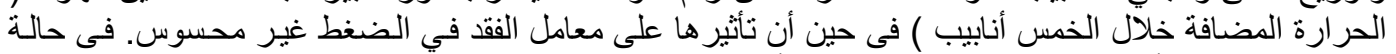

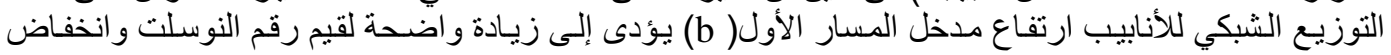

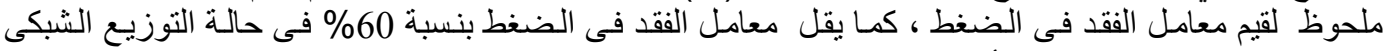

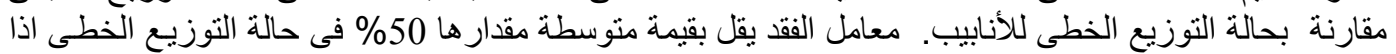

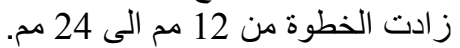

Keywords: Tube bandles, refrigeration plants, baffles, aspect ratio.

\section{INTRODUCTION}

Heat transfer and pressure drop characteristics of tube bundles have a great effect and play a vital role in the design of heat exchangers and industrial heat transfer equipments. For example, a common type of heat exchanger consists of a tube bundle with one fluid passing through the tubes and the other passing across the tubes. Frequently used tube bundle arrangements include the in-line and the staggered arrangements. Baffles are usually installed to increase the convection coefficient of the shell-side fluid by inducing turbulence and cross-flow velocity component. Many experimental studies on flow and heat transfer characteristics in a tube bank as well as relevant empirical equations were reported and derived for banks of plane and finned tubes as given in [1]. In these experimental studies on heat transfer, the measurements are often performed under the condition of a single test tube in the tube bank participates in heat or mass transfer or together. Fujii et al [2] presented a theoretical study for predicting overall heat transfer rate through a tube bank from the measurements with a single test tube placed in a dummy tube bank when the interference between temperature fields is significant. Gabriel et. al [3] studied numerically the effects of Prandtle and Reynolds numbers on the Nusselt number in the case of constant volumetric heat source for Reynolds number ranged from 0.05 to 40 . The study presents numerical computations of heat transfer over banks of square rods in aligned and staggered arrangements with porosity ranged from 0.44 to 0.98 . Khan et.al [4] studied analytically the heat transfer from an inline or staggered finned tube bundles arrangement. They employed an integral method of boundary layer analysis to derive closed form expression for the calculation of average heat transfer from tubes of a bank, which can be used for a wide range of parameters including longitudinal pitch transverse pitch, Reynolds and Prandtle numbers. Harris and Gold schmidt [5] studied experimentally the global external heat transfer coefficients for circular Ubends $\left(180^{\circ}\right.$ bends) in a cross flow air stream using six different curvature ratios covering a Reynolds 
number range of 3000- 80000 while imposing a uniform wall temperature boundary condition. Their measurements showed that the external heat transfer coefficients for circular U-bends in cross flow were found to be consistently higher than those for corresponding straight cylinder flows. Also, a strong dependence on the curvature ratio was observed. Also measurements showed that U-bend Nusselt numbers were found to be over four times larger than those for straight tubes of identical diameter and Reynolds number. Kuntysh and Stenin [6] presented an experimental data on heat transfer and pressure drop in the case of finned-tube bundles under cross flow. In this study several types of bandle arrangements were studied namely in- line, staggered and mixed.

Recently, heat exchangers are often operated in low Reynolds number range to reduce flow resistance and noise. When airflow in a heat exchanger is laminar, the interference between temperature fields around adjacent two tubes takes place. Therefore, the results for five test tubes differ from those for tube bank. Therefore, the aim of this work is to study experimentally heat transfer and pressure drop of isolated two-pass tube banks bundles with baffles at different locations. In the present study, five heated test tubes are located in two different arrangements; one is horizontal at the first row of the first pass and the other is vertical at the first column of the first pass. The test tubes are heated at different rates. The measurements are taken for the five test tubes. The length of the baffles and its location are taken into account. Also the effect of the tube banks aspect ratio is studied. From the measurements the local heat transfer coefficient and pressure drop are evaluated. All the measurements are conducted at low Reynolds numbers ranged from (1000 to 3500).

\section{THE EXPERIMENTAL TEST RIG AND MEASURING TECHNIQUES}

\subsection{The Experimental Test-Rig}

A schematic diagram of the experimental test rig for the present study is shown in Figs.1, 2. As shown in these figures, the test-rig consists of isolated tube banks with two-pass flow. The tube banks have the dimensions [215 x 125x80] $\mathrm{mm}$. The walls of the bank are made from isolated fiberglass sheets with thickness $7 \mathrm{~mm}$. The tube banks are arranged in-line initially and other arrangement is staggered. In the inline arrangement, the longitudinal and transverse pitches are $S_{L}=S_{t}=24 \mathrm{~mm}$. respectively while, for staggered arrangement, the pitches are, $S_{T}=24$ and $\mathrm{S}_{\mathrm{D}}=17 \mathrm{~mm}$. The unheated tubes were made from the copper, while the heated tubes were made from stainless- steel. The number of rows in the flow direction $n=17$ rows and in the transverse direction $\mathrm{m}=10$ columns. The tube outside diameter and length are $6.4 \mathrm{~mm}$ and $78 \mathrm{~mm}$, respectively. The tube banks have two-pass where the baffle plat directs the air flow. As a result of moving the baffle plate updown and forward - backward across the tubes, the height (b) of the first pass has the values 63, 51.5 and $38.5 \mathrm{~mm}$, while the entrance of the second pass (a) takes 40, 52 and $64 \mathrm{~mm}$. The airflow is delivered into the tube banks by using two blowers, (3), connected in series. The power of each blower is 900 Watts. The air discharge is controlled by the gate (2). The air flow rate through the tube banks is measured by a rotameter (4) at the outlet. The temperatures of the air at exit of the tube banks as well as, the temperatures of the heated tubes were measured by a calibrated thermocouple (5). The tested tubes were heated using an electric system consists of transformer (12) and voltage regulator (13) connected to stainless steel tubes. The number of heated tubes is five distributed at the entrance of the first pass. The pressure drop between the inlet and exit of the tube banks is measured using pressure taps connected to an inclined water U- tube manometer.

\subsection{Techniques of Measurements}

\subsubsection{Measuring Devices}

The temperature of the air at the tube banks exit and tested tubes are measured by using calibrated K- type thermocouples with $0.5 \mathrm{~mm}$ diameter which is connected to a digital temperature indicator. The temperature drop is taken as the arithmetical difference between the mean temperature of the tested tube surface and the mean temperature of the airflow.

The volume flow rate of the air flows through the tube banks is measured by a calibrated rotameter.

The static pressure drop between the inlet and the exit of the tube banks is measured using two static pressure tapes connected to an inclined water U-tube manometer.

\subsubsection{Evaluation of the measurements}

The experimental measurements are taken for two arrangements; the first one is concerned with in-line with different pitch, while the other is staggered. All measurements are conducted at low Reynolds numbers range $(1000 \leq \operatorname{Re} \leq 3500)$. The actual value of Reynolds number was calculated from the following relation:

$\mathrm{R}_{\mathrm{e}}=\mathrm{W}_{\text {max }}(\mathrm{d} / \mathrm{v})$

Where $\mathrm{W}_{\max }$ is the maximum velocity of the air in $\mathrm{m} / \mathrm{sec}$ and derived from the relation:

$\mathrm{W}_{\text {max }}=\mathrm{V}_{\text {air }} / \mathrm{A}_{\mathrm{f}}$,

Here, $\mathrm{V}_{\text {air }}$ is the volume flow rate of air measured by a calibrated rotameter, $v$ is the kinematic viscosity of air at mean temperature and $\mathrm{A}_{\mathrm{f}}$ is the area of flow and calculated as follows:

\section{For in - line arrangement}

$\mathrm{A}_{\mathrm{f}}=\mathrm{b} \mathrm{L-} \mathrm{Z}_{\mathrm{f}} \mathrm{d} \mathrm{L}$ 


\section{For staggered arrangement}

$\mathrm{A}_{\mathrm{f}}=\left(\mathrm{Z}_{\mathrm{f}}-1\right)\left(\mathrm{S}_{\mathrm{D}}-\mathrm{d}\right) * \mathrm{~L}$

Where $b$ is the height of the first pass, $\mathrm{m}, \mathrm{L}$ length of the tube (width of the test section) $\mathrm{m}, \mathrm{Z}_{\mathrm{f}}$ is the number of tubes in the traverse direction of the first pass and $\mathrm{S}_{\mathrm{D}}$ is the diagonal pitch.

The Nusselt number is calculated from the measured quantities as follows:

$\mathrm{Nu}=\frac{h \cdot d}{\lambda}$

Where, $\lambda$ is thermal conductivity calculated at mean temperature in $\mathrm{W} / \mathrm{m} \mathrm{k}$, and $\mathrm{h}$ is the coefficient of heat transfer for each tube and calculated from the relation:

$$
\mathrm{h}=\frac{Q}{A_{t}\left(T_{s}-T_{a}\right)} \quad \mathrm{W} / \mathrm{m}^{2}
$$

where: $\mathrm{Q}$ is the heat flux, and calculated from the relation $\mathrm{Q}=\mathrm{I} * \mathrm{~V}$ where $\mathrm{I}$ is the current, and $\mathrm{V}$ is the volt, $A_{t}$ is the outer surface of the heated tube and $\left(T_{s}-T_{a}\right)$ is the temperature difference between the surface temperature and air temperature.

The pressure drop coefficient, F, is calculated from the relation:

$$
F=\frac{2 \rho}{N G_{\text {max }}^{2} \cdot z} \cdot \Delta p
$$

Here, $G_{\max }$ is the maximum mass flow velocity rate $, \mathrm{kg} / \mathrm{m}^{2} \mathrm{sec}, \mathrm{N}$ number of tube rows in direction of flow which equal $34, \mathrm{Z}$ is a correction factor including the effect of tube bandle configuration ( $\mathrm{Z}=1$ for a square or equilateral triangle tube arrangement), $\quad \mathrm{G}_{\max }=\rho \mathrm{W} \max$.

All results are taken to evaluate the effect of baffle locations and other flow parameters on the characteristics of two-pass bank tube.

\section{RESULTS AND DISCUSSIONS}

In the case of in-line arrangement, the measurements are taken at fixed longitudinal, transverse pitch, $\mathrm{S}_{\mathrm{L}}=\mathrm{S}_{\mathrm{T}}=12 \mathrm{~mm}$ and entrance wide of the second pass $(\mathrm{a}=64 \mathrm{~mm})$, while the height of the first pass (b) has different values $(63,51.5 \& 38.5$ $\mathrm{mm})$. Figs. (3 a, b, c) show the variation of heat transfer coefficient $\mathrm{Nu}$ with mass flow velocity rate in dimensionless form $\mathrm{Re}$, at different heating rates (Q). As shown in the figure, the heat transfer coefficient increase with increasing the heating rate and mass flow rate. Figs. (4a, b, c) show the variations of pressure drop coefficient against Reynolds number at different heating rates. The figures show that, the effect of the heating rate on the friction coefficient is small. For staggered arrangement with transverse pitch $\mathrm{S}_{\mathrm{T}}=24 \mathrm{~mm}$, diagonal pitch $\mathrm{S}_{\mathrm{D}}=17 \mathrm{~mm}, \mathrm{a}=64 \mathrm{~mm}$, and variable values of $(b=63,51.5$, and 38.5$)$, Figs. ( $5 a, b, c)$, show the relation between $\mathrm{Nu}$ and $\mathrm{Re}$ at different heating rates. Also, Figs (6 a, b, c) show the variation of pressure drop coefficient against Reynolds number at the same conditions which given in Fig. 5. These figures show small values of pressure drop coefficient $\mathrm{F}$ were obtained except for $\mathrm{Q}=488 \mathrm{~W}$, b $=51.5 \mathrm{~mm}$. For in-line arrangement with the longitudinal and transverse pitch $\mathrm{S}_{\mathrm{L}}=\mathrm{S}_{\mathrm{T}}=24 \mathrm{~mm}$, a $=64 \mathrm{~mm}$ and $(\mathrm{b}=63,51.5, \& 38.8 \mathrm{~mm})$, Figs. (7 a, $\mathrm{b}, \mathrm{c})$, show the variations of Nusselt number with Reynolds number at different heating rates. The figures show that the same behaviour of increasing heat transfer coefficient with increasing in mass flow rate. Figures $(8-a, b, c)$ show the variation of pressure drop coefficient with Reynolds number at different heating rates for in-line arrangement with $\mathrm{S}_{\mathrm{L}}=\mathrm{S}_{\mathrm{T}}=$ $24 \mathrm{~mm}$. The effect of changing the first-pass height (b) on the heat transfer coefficient at constant heating rate $(\mathrm{Q}=20 \mathrm{~W})$ for constant second-pass entrance $(\mathrm{a}$ $=64 \mathrm{~mm}$ ) is shown in Fig. 9. The results show that the heat transfer coefficient increases with increasing (b) as well as increasing the flow rate. Also, the effect of the first-pass height (b) on the pressure loss coefficient at constant heating rate and constant second-pass entrance $(\mathrm{a}=64 \mathrm{~mm})$ is shown in Fig. 10. The figure shows that the pressure loss coefficient increases with decreasing (b) as a result of the flow area decrease. The effect of changing the wide of the second-pass entrance (a) on the heat transfer coefficient at constant heating rate and the height of the first-pass (b) is plotted in Fig. 11. The figure shows that the heat transfer coefficient have maximum values at $\mathrm{a}=40 \mathrm{~mm}$ and minimum values at, $\mathrm{a}=52 \mathrm{~mm}$ where values corresponding to, $\mathrm{a}=64$ $\mathrm{mm}$ lie between them. It is clear that $\mathrm{a}=40 \mathrm{~mm}$ is approximaty the best choice of the baffle location. Also the same ressult is shown in Fig. 12. The Figure shows the effect of the wide of the second-pass entrance $(\mathrm{a}=64,52 \& 40 \mathrm{~mm})$ on the pressure loss coefficient $(\mathrm{F})$ at constant heating rate $(\mathrm{Q}=20 \mathrm{~W}$ ) and the height of the first-pass $(b=63 \mathrm{~mm})$. At constant heating rate $(\mathrm{Q}=17 \mathrm{~W})$ and constant values of $\left(a=52 \mathrm{~mm}, b=51.5 \mathrm{~mm} \mathrm{\&} \mathrm{S}_{\mathrm{T}}=24\right.$ $\mathrm{mm}$ ) the effect of the tube bank arrangement on the heat-transfer coefficient is shown in the Fig. 13. The results show that the heat-transfer coefficient in staggered arrangement is larger than that for in-line arrangement. This is may be due to the increase of turbulence intensity, which exists in the case of staggered arrangement. Fig. 14, shows the effect of tube bank arrangement on the pressure loss coefficient at constant, heating rate $(\mathrm{Q}=17 \mathrm{~W})$, and constant values of $\left(\mathrm{a}=52 \mathrm{~mm}, \mathrm{~b}=51.5 \mathrm{~mm} \& \mathrm{~S}_{\mathrm{T}}=\right.$ $24 \mathrm{~mm})$. The figure shows that the pressure loss 
coefficient in the case of staggered arrangement is smaller than that in the case of inline arrangement. The effect of the pitch $\left(\mathrm{S}_{\mathrm{T}}\right)$ and heating rate $(\mathrm{Q}=16$ $\mathrm{W} \& 70 \mathrm{~W})$ for in-line arrangement at $(\mathrm{a}=40 \mathrm{~mm})$ and $(b=38.5 \mathrm{~mm})$ on the heat-transfer coefficient is shown in Fig. 15. The figure shows that at low values of heat rate $(\mathrm{Q}=16 \mathrm{~W})$ the heat-transfer coefficient has lower values than for higher value of $(\mathrm{Q}=70 \mathrm{~W})$. Also, the effect of changing the pitch $\left(\mathrm{s}_{\mathrm{T}}=12 \mathrm{~mm} \& 24 \mathrm{~mm}\right)$ and heating rate $(\mathrm{Q}$ $=16 \& 70 \mathrm{~W})$ for in-line arrangement $(\mathrm{a}=40 \mathrm{~mm}$ and $b=38.5 \mathrm{~mm}$ ) on the pressure loss coefficient is shown in Fig. 16. The figure shows that the pressure loss coefficient decreases with increasing the pitch, but the effect of increasing the heating rate on pressure loss coefficient is small.

\section{CONCLUSION}

The previous analysis of the experimental results leads to the following conclusions:

1 ) The heat transfer coefficient $(\mathrm{Nu})$ increases as the heating rate increase at the same value of ( a ) and ( b ) for all examined arrangements, while the change in pressure loss coefficient is very small.

2) The increase of the height of the first pass b increases the heat transfer coefficient and decreases the pressure loss coefficient at constant heating rate and constant value of ( a ) for all examined arrangements.

3) The entrance wide of the second-pass a has a great effect on the heat transfer coefficient and pressure loss coefficient, for the all examined arrangements.

4) For in-line arrangement, increasing the tube pitch increases the heat transfer coefficient in the range of low Reynolds number $\operatorname{Re}<2500$ while for high Reynolds number $\mathrm{Re}>2500$ the heat transfer coefficient decreases.

5) For in-line arrangement, increasing the tube pitch decreases the pressure loss coefficient.

6) For the same flow conditions, the staggered arrangement has a higher value of heat transfer coefficient and lower pressure loss coefficient than that of in-line arrangement.

\section{Nomenclatures:}

$\begin{array}{clr}A_{f} & \text { Air flow area } & \mathrm{m}^{2} \\ A_{t} & \text { tube surface area } & \mathrm{m}^{2} \\ \mathrm{a} & \text { Entrance wide of the second pass } & \mathrm{m} \\ \mathrm{b} & \text { Height of the first pass } & \mathrm{m} \\ \mathrm{d} & \text { Outside diameter of the tube } & \mathrm{m} \\ \mathrm{G}_{\max } & \text { Max. mass flow velocity } & \mathrm{Kg} / \mathrm{m}^{2} . \mathrm{sec} \\ \mathrm{h} & \text { Heat transfer coeff. of air } & \mathrm{W} / \mathrm{m}^{2}{ }^{\circ} \mathrm{C} \\ \mathrm{h}_{\mathrm{m}} & \text { Mean heat transfer coeff. } & \mathrm{W} / \mathrm{m}^{2}{ }^{\circ} \mathrm{C} \\ \mathrm{I} & \text { Current } & \mathrm{Amp} .\end{array}$

L Length of the tube m

Q Heat flux Watt

$\mathrm{S}_{\mathrm{D}} \quad$ Diagonal pitch m

$\mathrm{S}_{\mathrm{L}} \quad$ Longitudinal pitch $\mathrm{m}$

$\mathrm{S}_{\mathrm{T}}$ Transverse pitch m

$\mathrm{T}_{\mathrm{s}} \quad$ Surface temperature $\mathrm{K}$

$\mathrm{V}$ Volt volt

$\mathrm{V}_{\text {air }} \quad$ Volumetric flow rate $\mathrm{m}^{3} / \mathrm{sec}$

$\mathrm{W}_{\max }$ Max. air velocity $\mathrm{m} / \mathrm{sec}$

$\lambda_{\text {air }} \quad$ Thermal conductivity of air $\quad \mathrm{W} / \mathrm{m} . \mathrm{k}$

$\rho \quad$ Density $\mathrm{Kg} / \mathrm{m}^{3}$

$v \quad$ Kinematics viscosity of air $\quad \mathrm{m}^{2} / \mathrm{sec}$

$\triangle \mathrm{P} \quad$ Pressure drop $\quad \mathrm{Pa}$

Dimensionless Quantities :-

Re Reynolds number $=\mathrm{W}_{\max } \cdot \mathrm{d} / \mathrm{v}$

$\mathrm{Nu} \quad$ Nusslet number $=$ h.d $/ \lambda_{\text {air }}$

$\mathrm{Nz} \quad$ Number of the heating tubes

$\mathrm{Z} \quad$ Correction factor

$\mathrm{Z}_{\mathrm{f}} \quad$ Number of the tubes in the transverse direction for the first pass.

F pressure loss coefficient.

\section{REFERENCES}

[1] Zukauskas,A. and Ulinskkas ,R., Banks of plain and finned tubes, "Heat Exchanger Design Hand book ", 2.2.4, hemisphere, 1983.

[2] Fujii, A. , Fujii,T. and Sato, R. , A "Theoretical consideration for prediction heat transfer characteristics of a tube bank from measurements with a single test tube ", 8th International Heat Transfer Conference V.6 , 1986.

[3] Gabrriel , G. , Michel, F., M. and Stephane , LePersons , "Numerical study of heat transfer over banks of rods in small Reynolds number cross flow ", International Journal of Heat and Mass Transfer 51(2008) 853- 864.

[4] Khan,W., A., Culham, J.,R., and Yovanovich, M., M., "Convection heat transfer from tube banks in cross- flow :Analytical approach ". International Journal of Heat and Mass Transfer vol. 49 (2006) 4831- 4838.

[5] Harris , D., K., and Golld schmidt, V., W., "An empirical investigation into the external heat transfer of a U-bend in cross flow ", International Journal of Heat and Mass Transfer 42(1999) 1957-1968.

[6] Kuntysh,V., B. and Stenin, N., N., "Heat transfer and pressure drop in cross flow through mixed in line - staggered finned tube bundles ", Thermal Engineering ,vol.40 No. 2., 1993 


\section{ERJ}

Engineering Research Journal

Faculty of Engineering

Minoufiya University

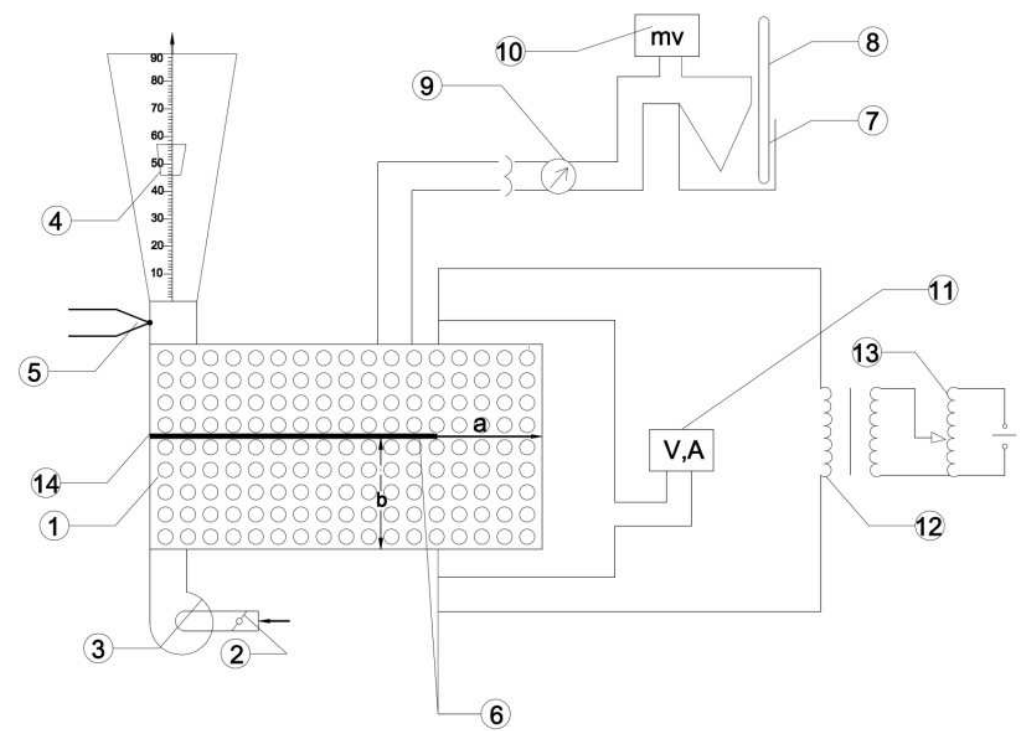

1-Wall of the bank.

8- Thermometer.

2- The air inlet.

9- Selector.

3- Blower.

10- Melli-voltmeter.

4- Rota meter.

11 - Avometer.

5- Thermocouple.

12-Transformer.

6- Tube.

13-Voltage regulator.

7- Thermocouple cold point.

14-Baffle.

Fig. 1. Experimental set-up

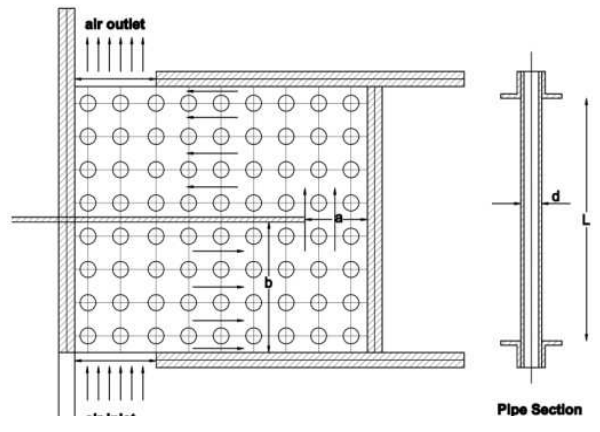

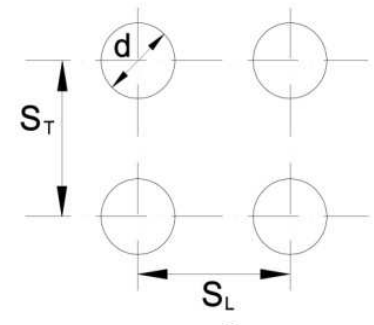

in line arrangement

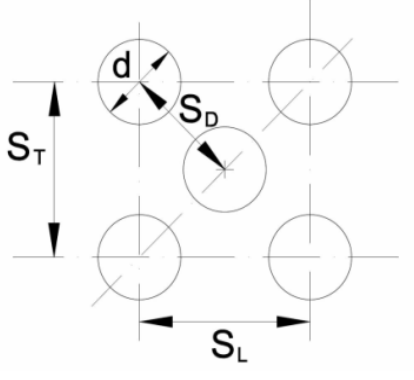

Staggared arrangement

Fig. 2. A schematic diagram of the test section 


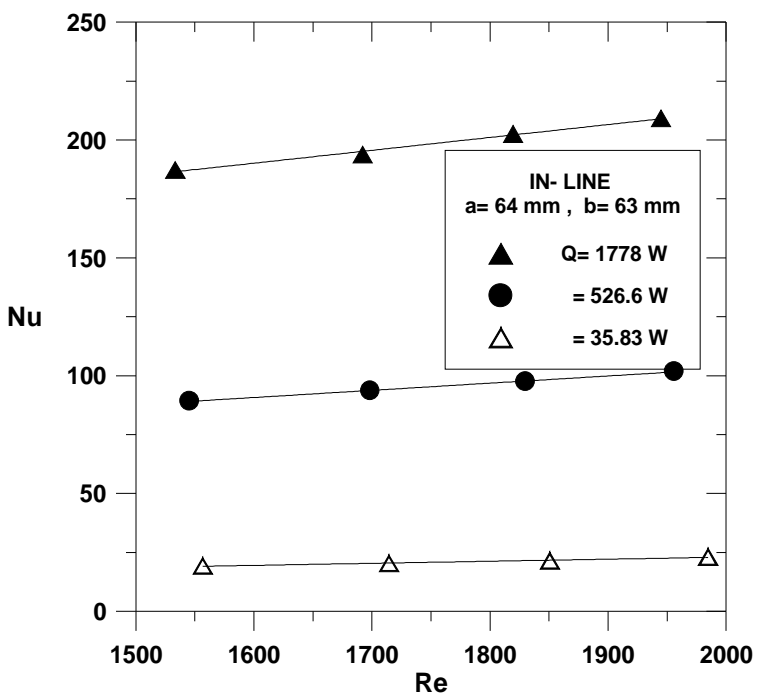

(a)

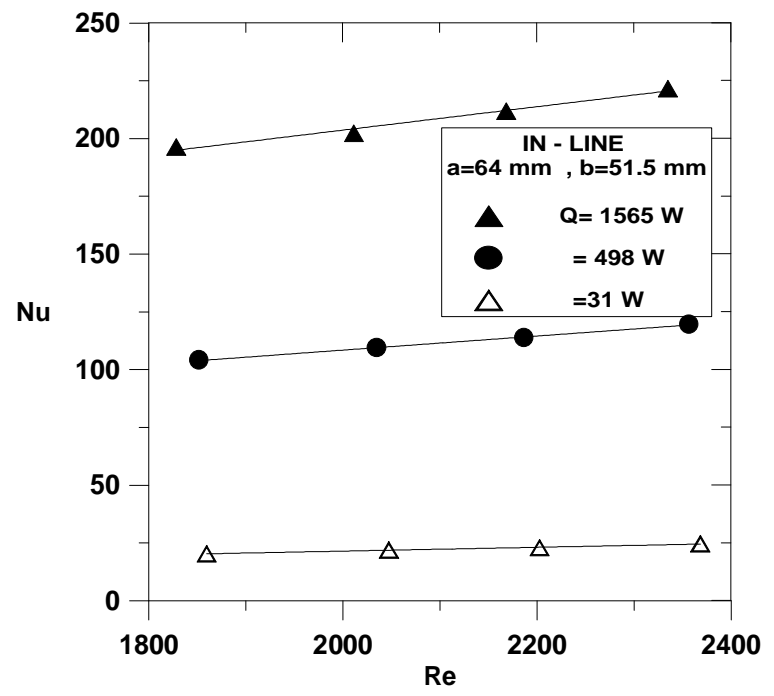

(b)

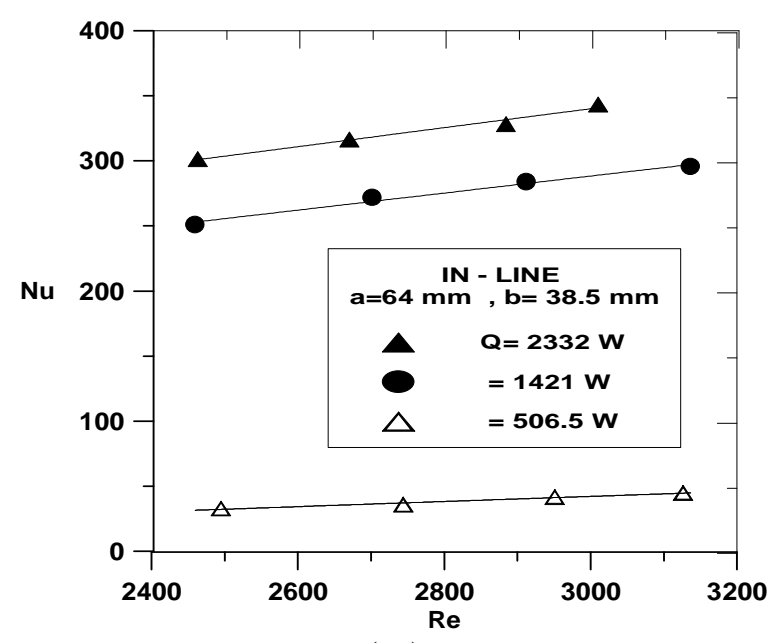

( c )
Fig. 3. The variation of $(\mathrm{Nu})$ with $(\mathrm{Re})$ at different values of heating rates

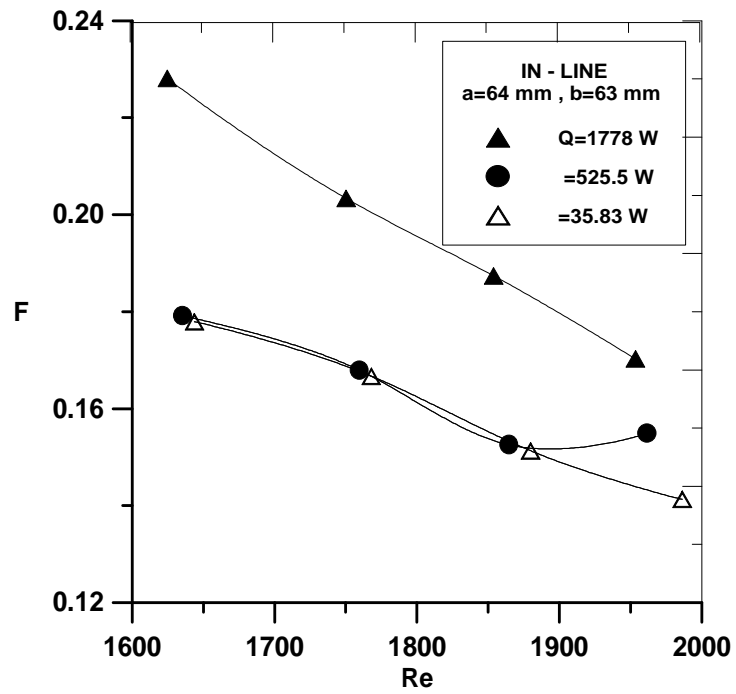

(a)

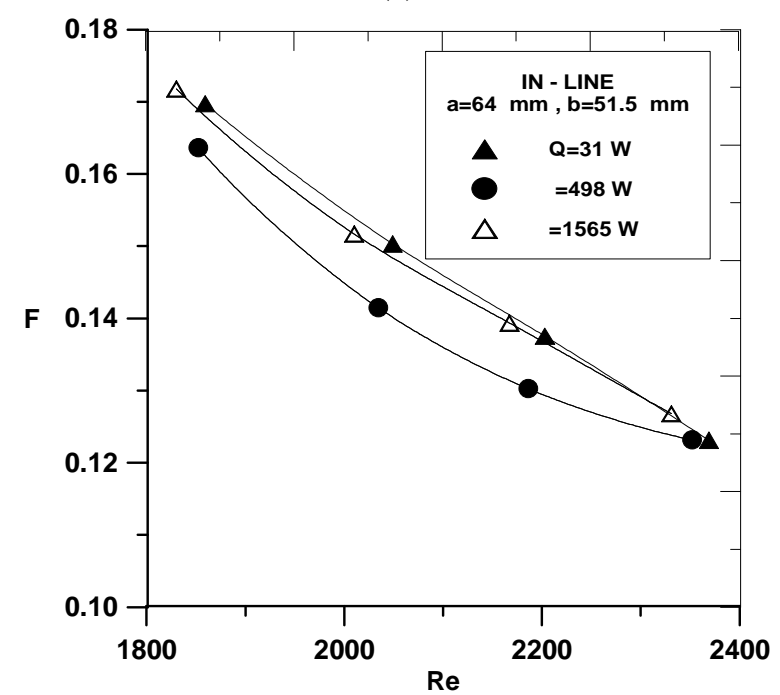

(b)

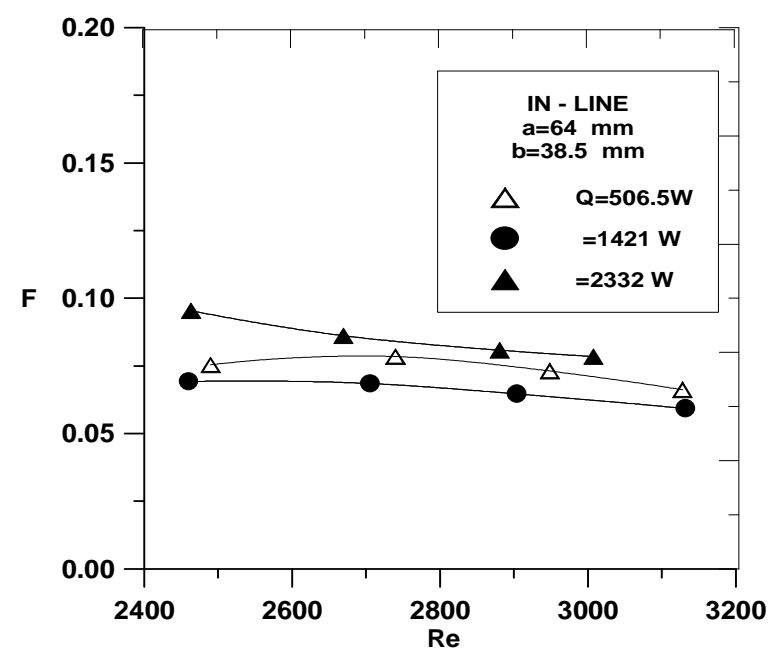

( c ) 
F. Sh. Abou-Taleb, "Experimental Study of Heat Transfer and Pressure Drop of Two-Pass Tube Banks"

Fig .4. Variation of pressure drop coefficient $(\mathrm{F})$ with

$(\mathrm{Re})$ at different values of heating rates

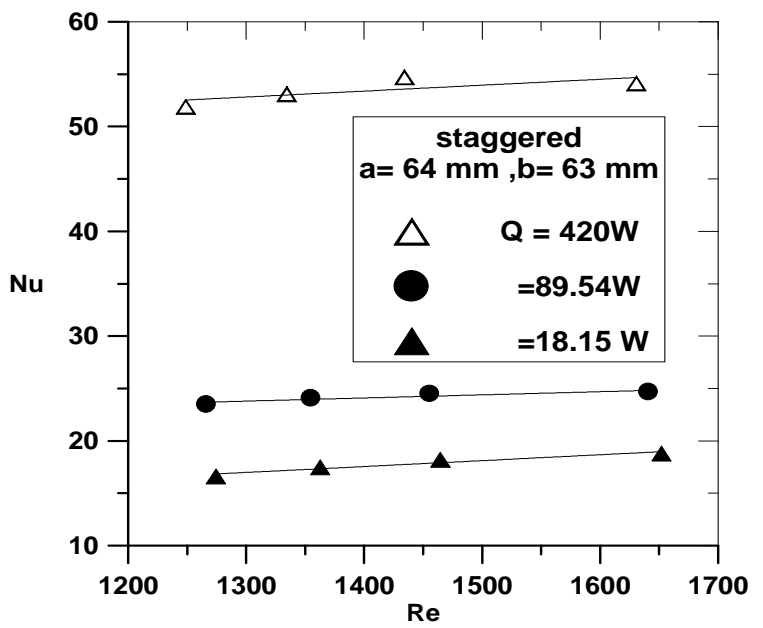

(a)

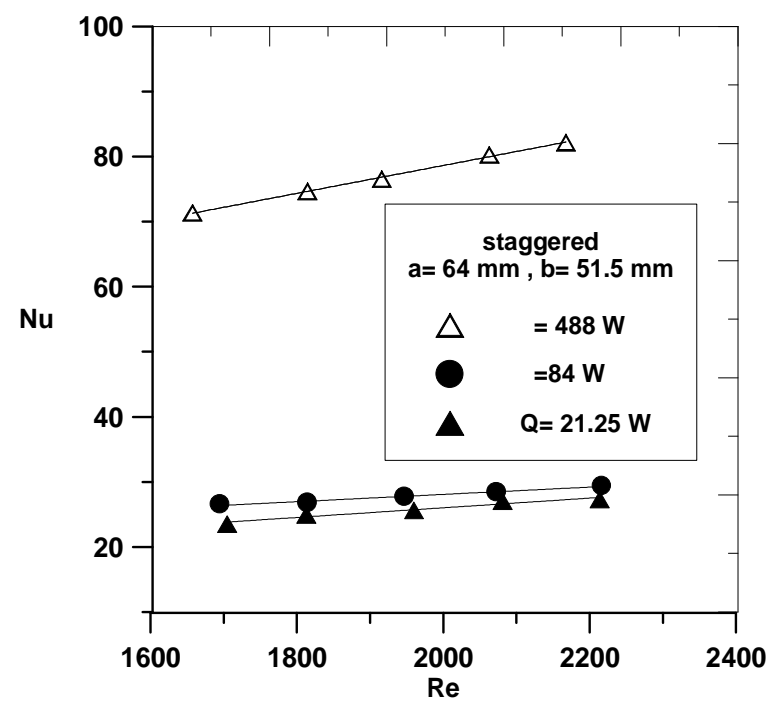

(b)

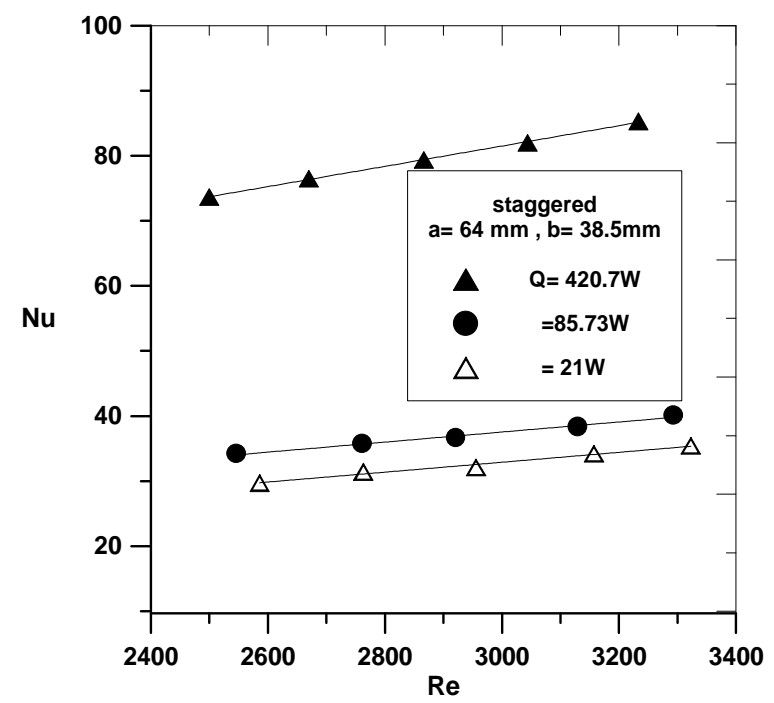

(c)
Fig .5. Variation of $\mathrm{Nu}$ with $\mathrm{Re}$ at different values of heating rates for staggered arrangement with $S_{D}=17 \mathrm{~mm} \mathrm{\&} S_{T}=24 \mathrm{~mm}$

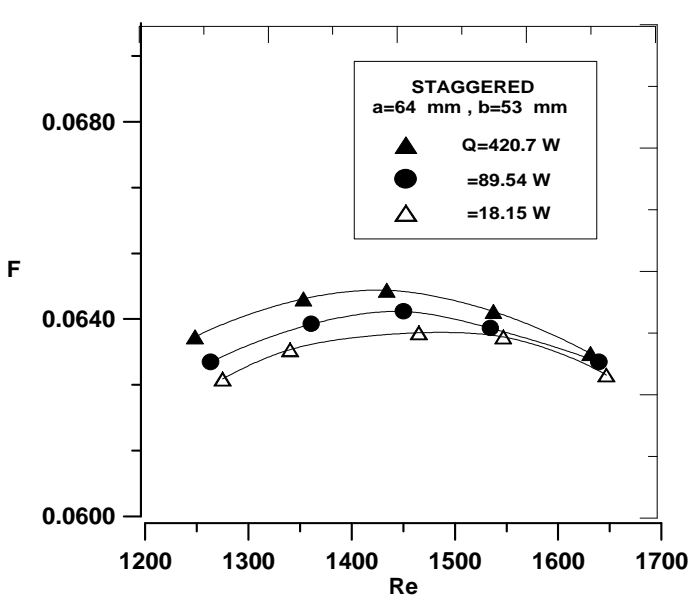

(a)

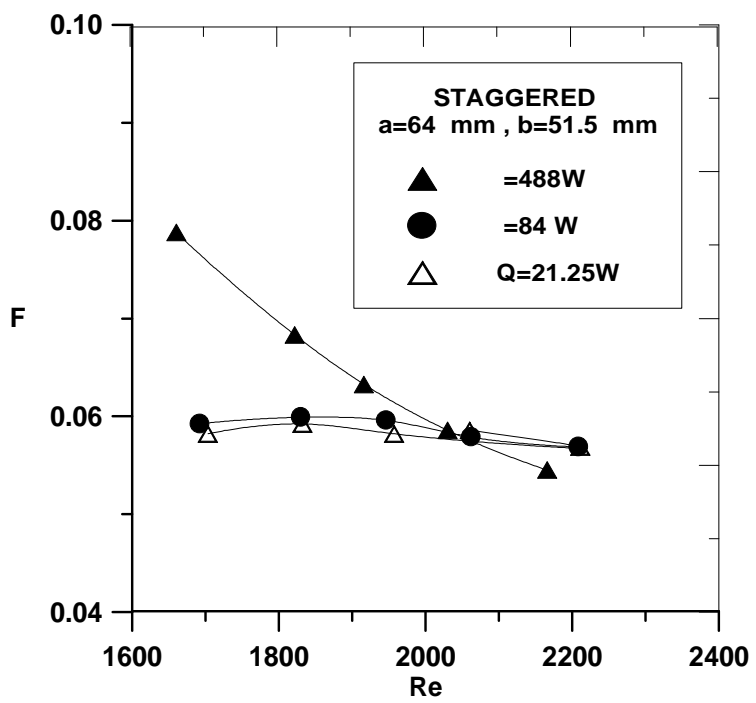

(b)

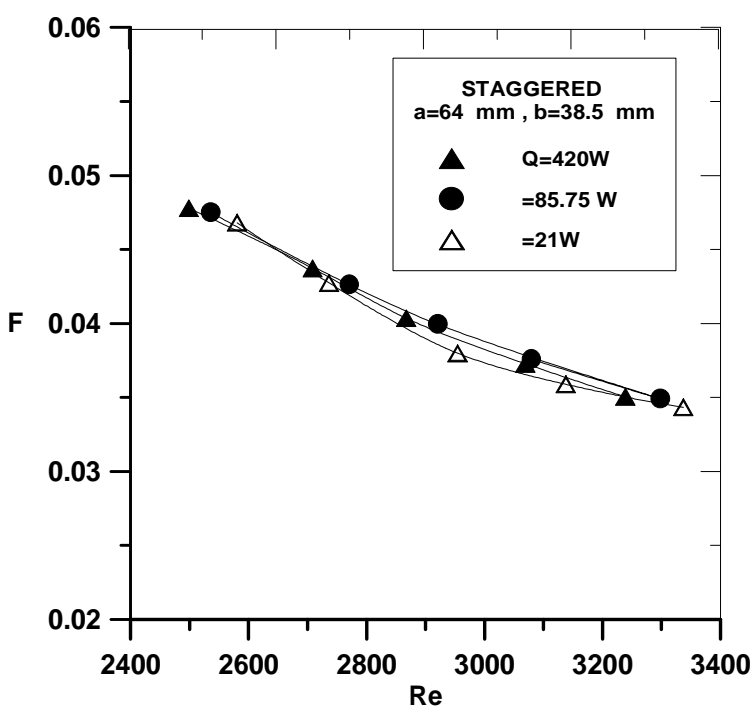

(c) 
F. Sh. Abou-Taleb, "Experimental Study of Heat Transfer and Pressure Drop of Two-Pass Tube Banks"

Fig. 6. Variation of pressure drop coefficient $(\mathrm{F})$ with $(\mathrm{Re})$ at different values of heating rates for staggered arrangement with $\mathrm{S}_{\mathrm{D}}=17 \mathrm{~mm}$

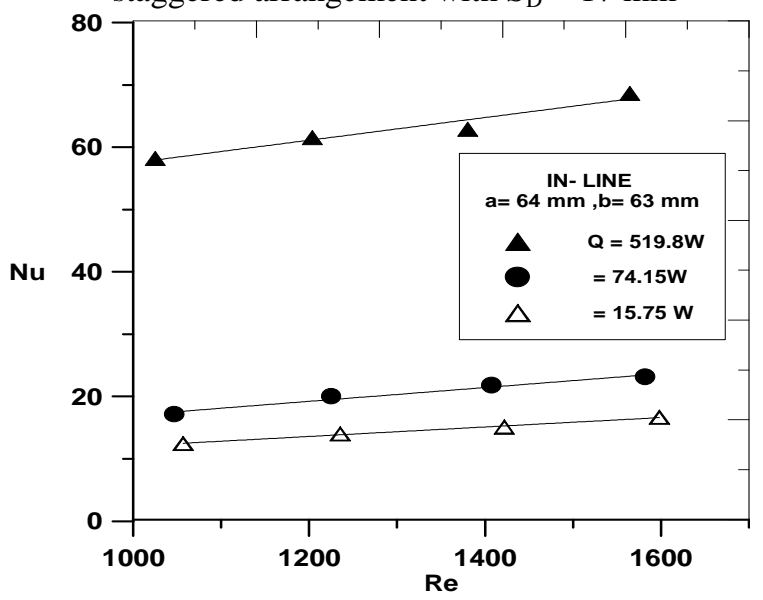

(a)

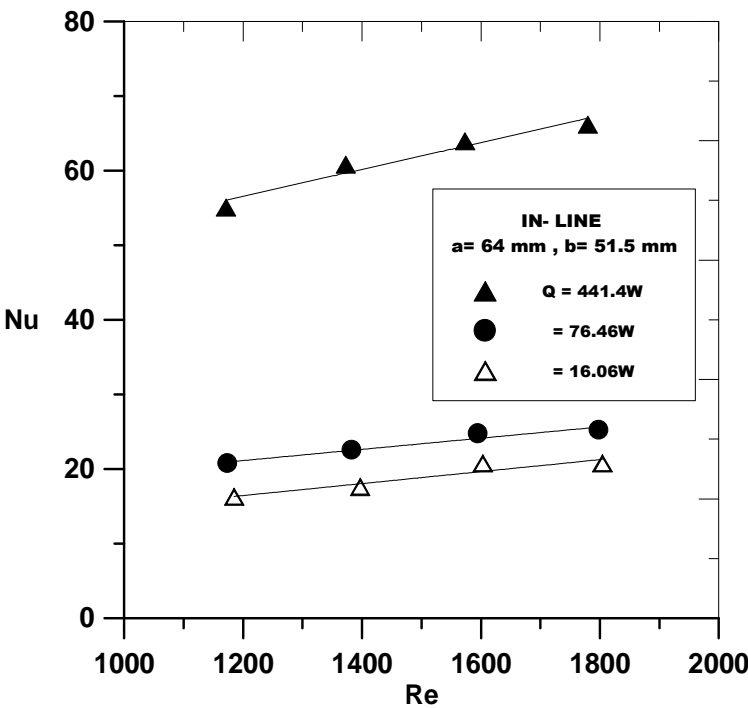

(b)

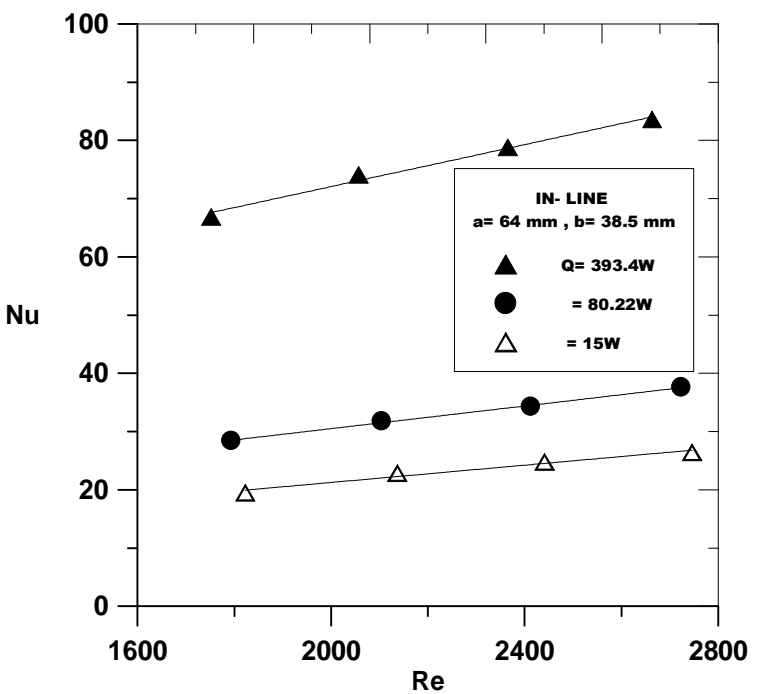

(c)
Fig.7. Variation of $(\mathrm{Nu})$ with $(\mathrm{Re})$ at different values of heating rates for in line arrangement with $\mathrm{S}_{\mathrm{T}}=\mathrm{S}_{\mathrm{L}}=24 \mathrm{~mm}$

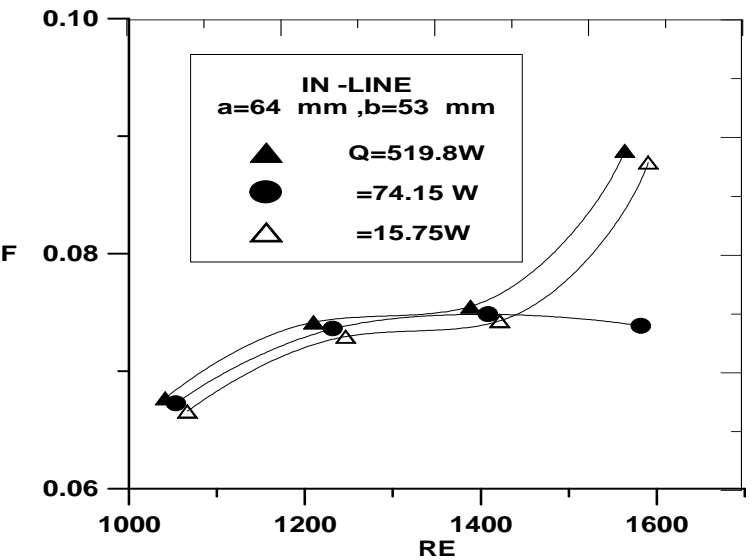

(a)

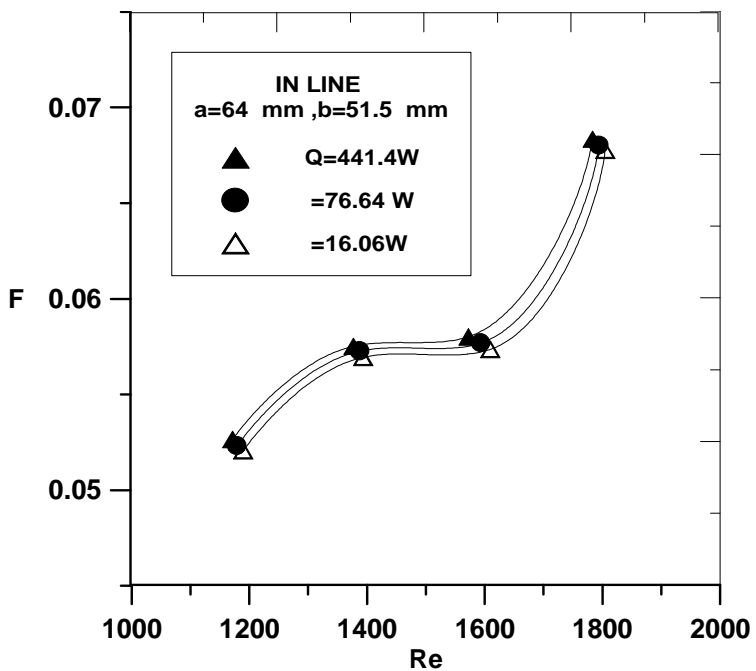

(b)

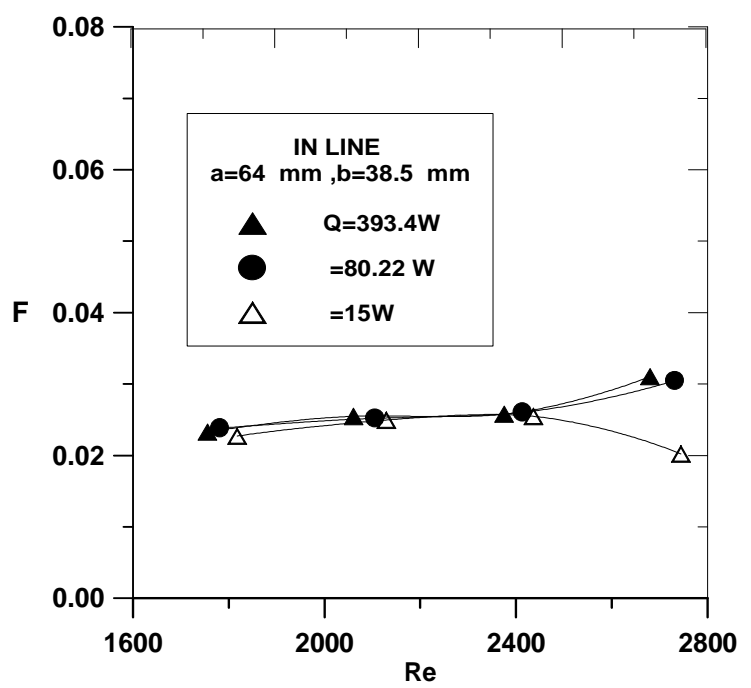

(c) 
Fig. 8. Variation of pressure drop coefficient (F) with $(\mathrm{Re})$ at different values of heating rates for inline arrangement with $\mathrm{S}_{\mathrm{L}}=\mathrm{S}_{\mathrm{T}}=24 \mathrm{~mm}$

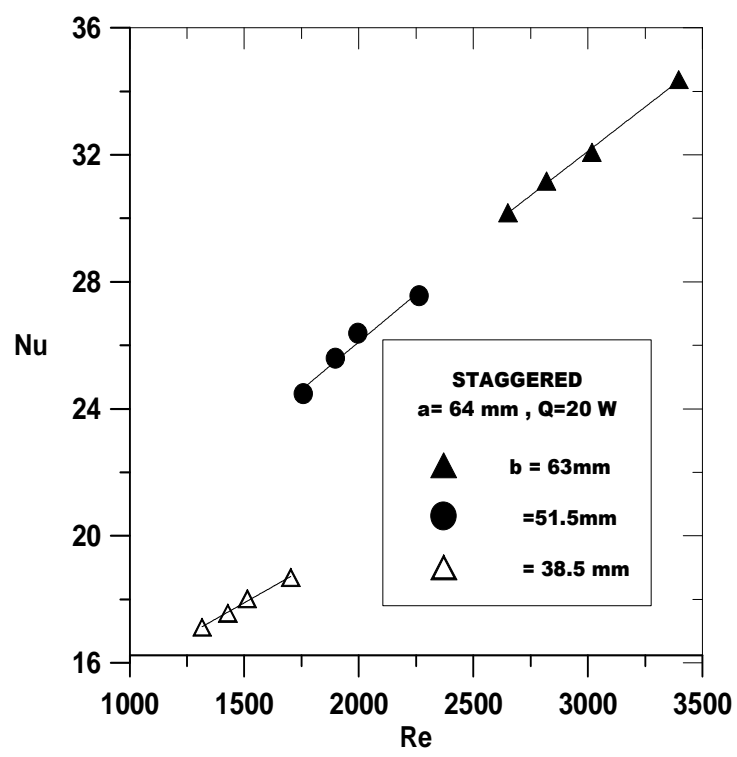

Fig. 9. The variation of of $(\mathrm{Nu})$ with $(\mathrm{Re})$ at different values of heights (b) at $\mathrm{a}=64 \mathrm{~mm}$ and $\mathrm{Q}=20 \mathrm{~W}$

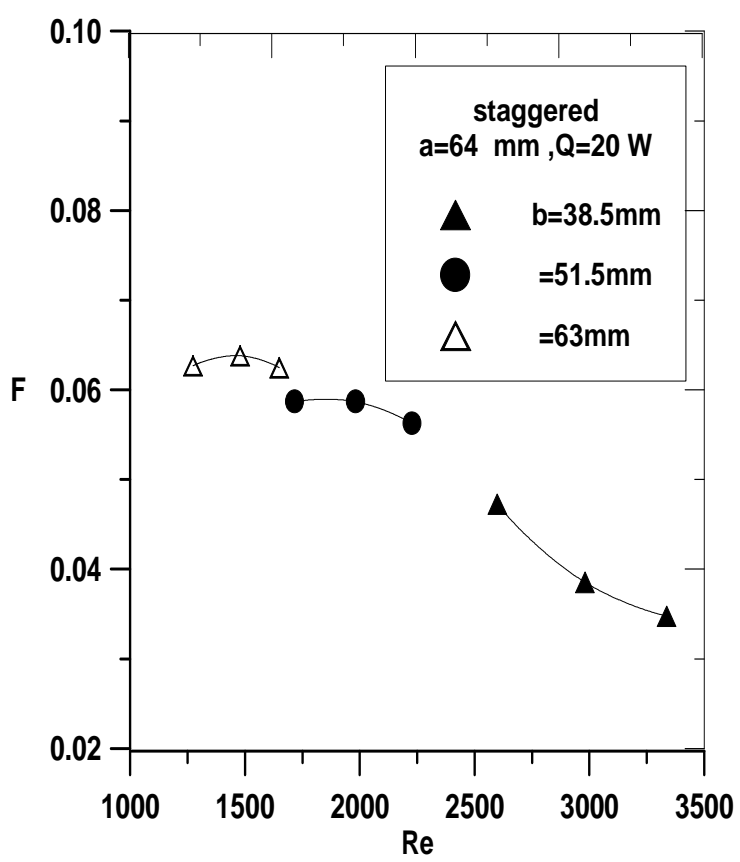

Fig. 10. The variation of pressure drop coefficient (F) with (Re) at different values of height (b) at $\mathrm{a}=64 \mathrm{~mm}$ and $\mathrm{Q}=20 \mathrm{~W}$

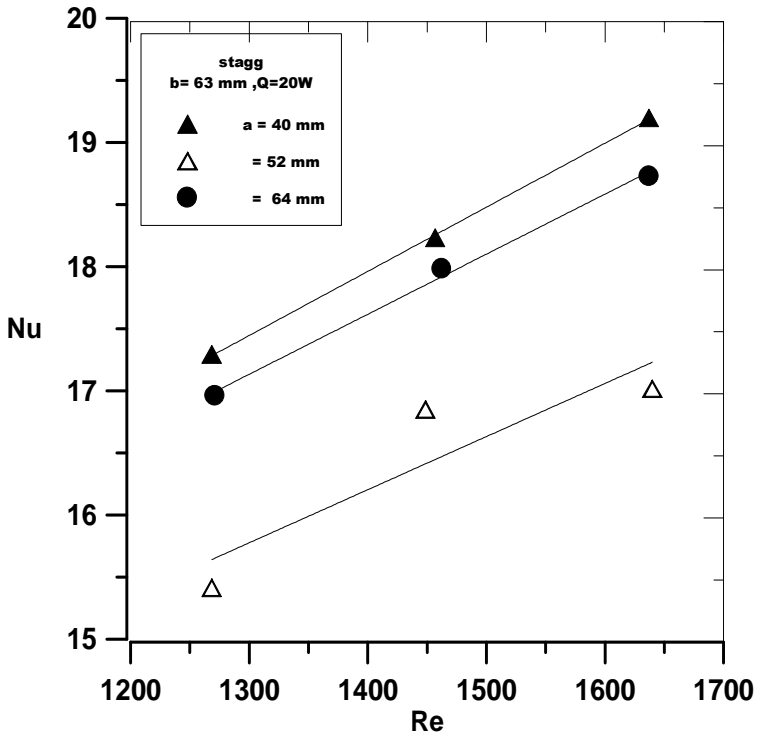

Fig. 11. The variation of of $(\mathrm{Nu})$ with $(\mathrm{Re})$ at different values of (a) for staggered arrangement at $\mathrm{b}=63 \mathrm{~mm}$ and $\mathrm{Q}=20 \mathrm{~W}$

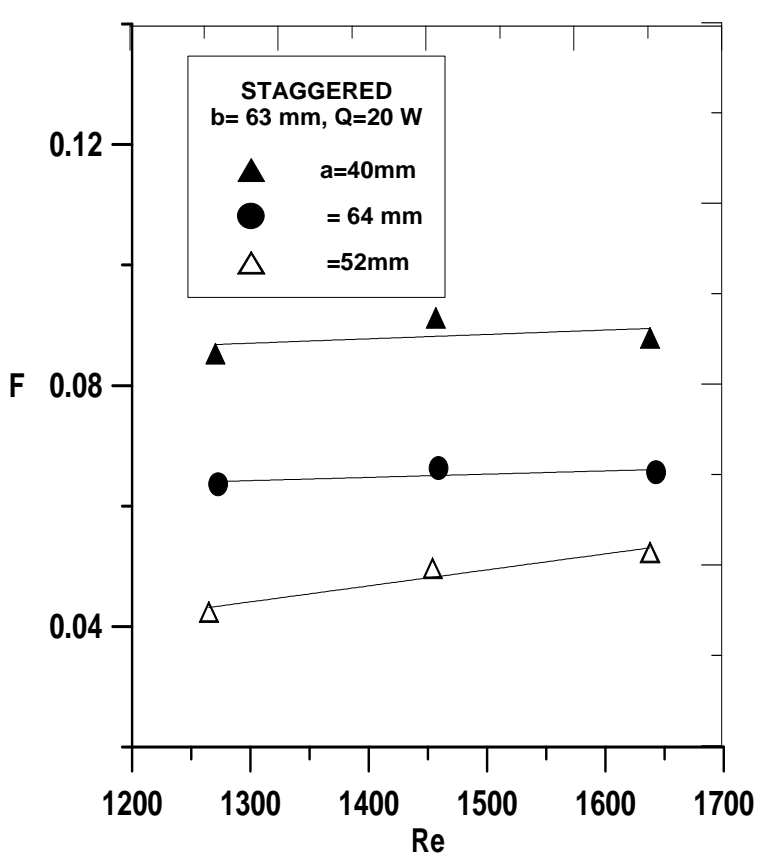

Fig .12. The variation of pressure drop coefficient (F) with ( $R e$ ) at different values of (a) at $b=63$ $\mathrm{mm}$ and $\mathrm{Q}=20 \mathrm{~W}$ 


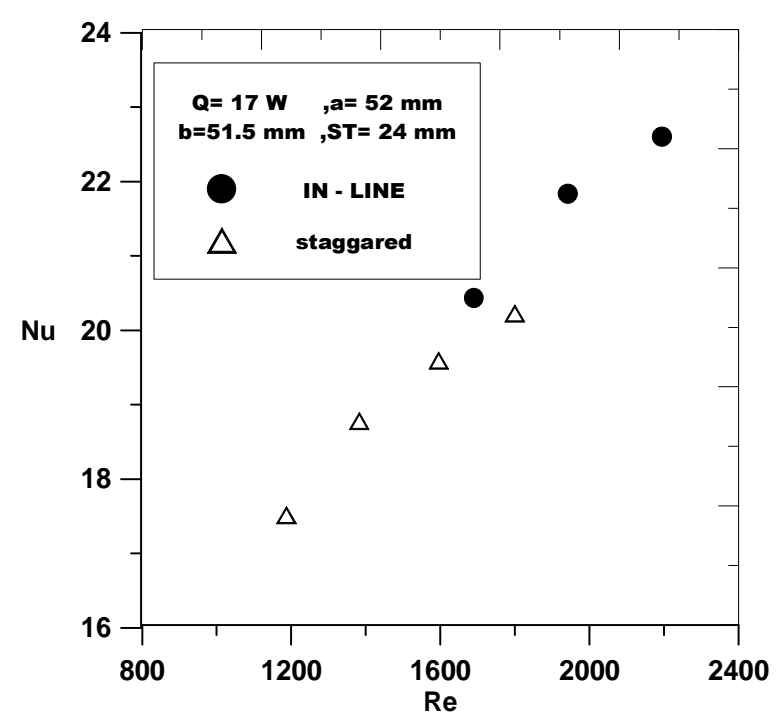

Fig. 13. The effect of the tube bank arrangement on the heat transfer rate at $\mathrm{Q}=17 \mathrm{~W}$

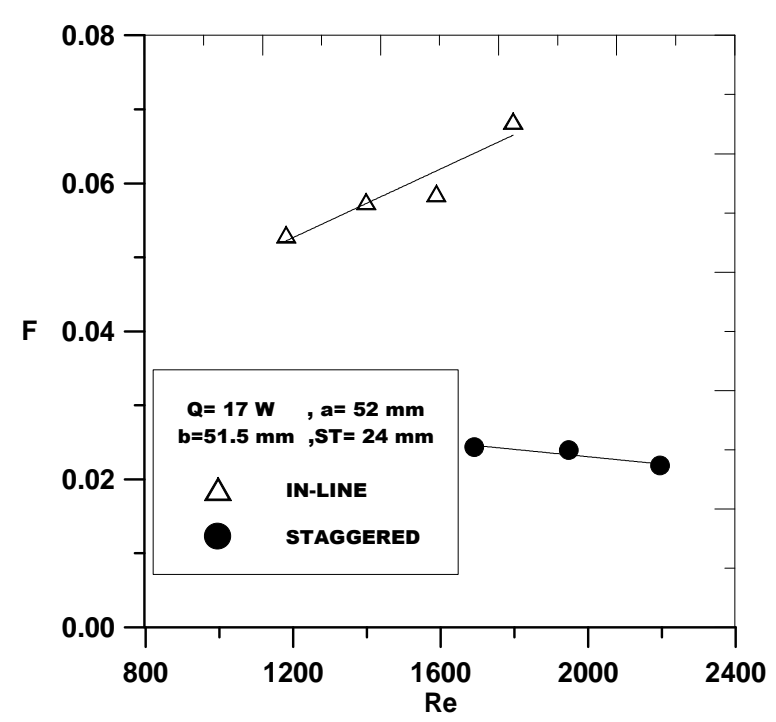

Fig. 14. Effect of the tube bank arrangement on the pressure drop coefficient $(\mathrm{F})$ at $\mathrm{Q}=17 \mathrm{~W}$

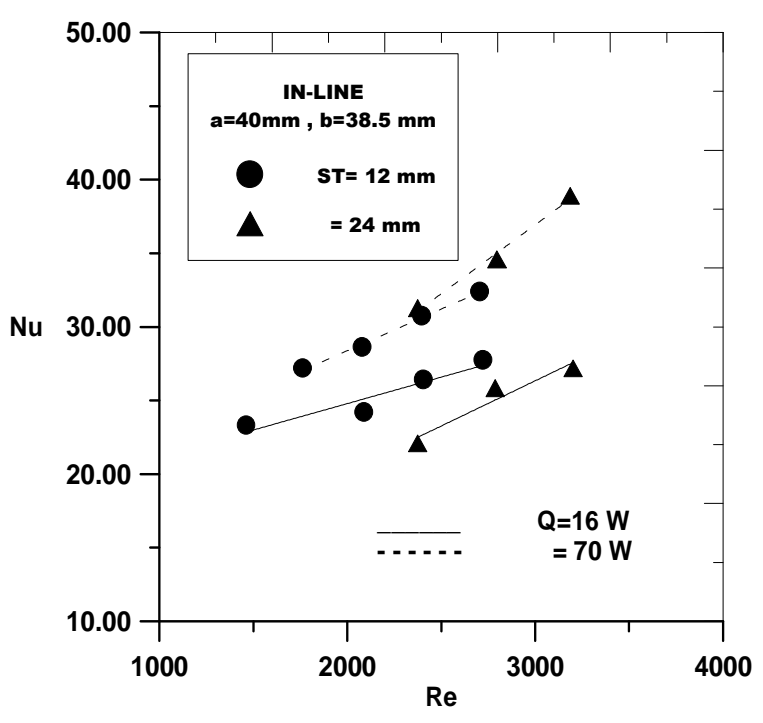

Fig. 15. The effect of pitch on the heat transfer rate at $\mathrm{a}=40 \mathrm{~mm}, \mathrm{~b}=38.5 \mathrm{~m}$ for two values of $\mathrm{Q}$

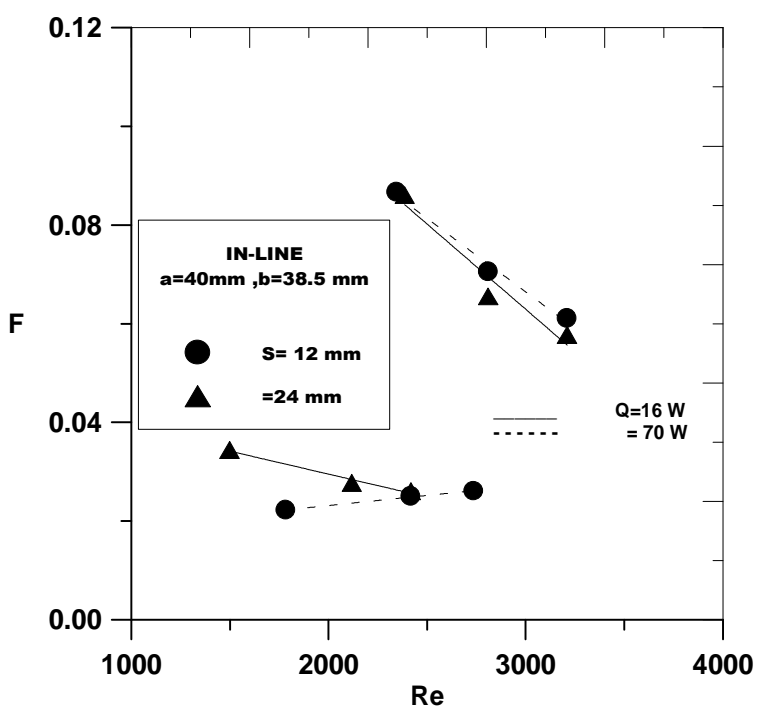

Fig. 16. The effect of pitch on the pressure drop coefficient (F) at $a=40 \mathrm{~mm}, b=38.5 \mathrm{~mm}$ for two values of $\mathrm{Q}$ for in-line arrangement 